\title{
Did Time Inconsistency Contribute to the Great Inflation? Evidence from the FOMC Transcripts
}

\author{
Henry W. Chappell, Jr. \\ Department of Economics \\ University of South Carolina \\ Columbia, South Carolina 29208 \\ chappell@darla.badm.sc.edu \\ Rob Roy McGregor \\ Department of Economics \\ University of North Carolina at Charlotte \\ Charlotte, North Carolina 28223 \\ rrmcgreg@email.uncc.edu
}

This is a revised version of a paper originally presented at the annual meeting of the Public Choice Society, March 10-12, 2000, in Charleston, SC. We acknowledge the able research assistance of Matthew Birmingham, Susan Harden, Yoko Kawakami, Steven Nape, Matthew Neidell, Ann Poovey, Paul Prochaska, David Ramsey, Souren Soumbatiants, and Todd Vermilyea. William Dougan, seminar participants at Clemson University and the University of South Carolina, and two anonymous referees have provided helpful comments. Financial support was provided by National Science Foundation grants SBR-9422850 and SBR-9423095.

April 28, 2003 


\title{
Did Time Inconsistency Contribute to the Great Inflation? Evidence from the FOMC Transcripts
}

\begin{abstract}
We use evidence from detailed records of FOMC deliberations to argue that the theory of the time inconsistency problem provides a reasonable explanation of the Federal Reserve's excessively expansionary policy stance during the 1970-1978 period when Arthur Burns chaired the Board of Governors. The records suggest that the Fed perceived a Phillips curve tradeoff and political pressures that made it difficult to adopt disinflationary policies at any moment in time; the tendency toward excessively expansionary policy was exacerbated by the short-run planning horizon the Committee faced in each of a sequence of meetings. We further argue that comparative static predictions of the time inconsistency model are consistent with both the rise of inflation during the Burns years and its subsequent fall.
\end{abstract}




\section{Did Time Inconsistency Contribute to the Great Inflation? Evidence from the FOMC Transcripts}

The time inconsistency problem is often invoked to explain an inflationary bias alleged to plague central banks. ${ }^{1}$ The assumptions behind the reasoning are as follows. First, the central bank is assumed to choose policy actions on a period-by-period basis in each of its meetings; it is not constrained by rules, but instead uses discretion in each period. Second, public expectations of inflation for the upcoming period are viewed as given at the time of the meeting. Third, the economy can be characterized by an expectational Phillips curve; i.e., if inflation is higher than the public expects, unemployment will temporarily fall below its natural rate. Fourth, the central bank values a marginal reduction of unemployment below its natural rate, but is also averse to higher inflation. Finally, it is assumed that expectations are rational.

With predetermined inflation expectations, the central bank sees an opportunity to lower unemployment via surprise money growth in each of its meetings. If expected inflation were zero, for example, the reduction in unemployment created by a money growth surprise would be "worth" the modest increase in inflation. However, a problem arises when public expectations are rational. The public, understanding the Fed's objectives, will correctly anticipate monetary stimulus, rendering the effort to reduce unemployment ineffective. Instead, the result is inflation. At the equilibrium level of inflation, the marginal gains from unemployment reduction are balanced by the added costs of additional inflation in the current period. This is suboptimal in comparison to a

\footnotetext{
${ }^{1}$ Seminal contributions include Kydland and Prescott (1977) and Barro and Gordon (1983).
} 
zero inflation outcome, but the latter is not an equilibrium in the absence of credible precommitment.

Alan Blinder (1997), a former Governor of the Federal Reserve, has argued that the time inconsistency literature is largely irrelevant to present-day monetary policymaking. His argument is a simple one. If members of the Federal Open Market Committee (FOMC) understand that attempts to drive unemployment below its natural rate will ultimately be unsuccessful, they will not attempt it. DeLong (1997, p. 265) says that he has "found no sign in Federal Reserve deliberations in the 1970s that timeinconsistency issues - either that future central bankers would not carry out the policies to which earlier central bankers had tried to commit them, or that the private sector would fail to believe long-run commitments to a low-inflation policy-played any role in policy formation." Similarly, Mayer (1999, p. 8) concludes, "All in all, it would be hard to write a reasonable history of Fed policy in which time inconsistency plays a major role.”

Persson and Tabellini (2000), however, argue that these criticisms miss the point, since time inconsistency analysis does not predict that the Fed would want to generate policy surprises in equilibrium. Rather, in an inflationary equilibrium, the Fed's lack of credibility would cause a more restrictive policy to produce a recession. As a consequence, the Fed would refrain from pursuing a disinflationary policy. Some empirical evidence also supports the relevance of the time inconsistency theory of monetary policy. Ireland (1999) notes that the Barro-Gordon model predicts a positive association between the natural rate of unemployment and the equilibrium inflation rate; econometric results that build on this observation “can successfully explain inflation's initial rise and subsequent fall over the past four decades" (Ireland, 1999, p. 283). 
In this paper, we investigate the relevance of time inconsistency theory in an alternative way. Specifically, we adopt a narrative approach, using historical evidence from records of FOMC deliberations to evaluate the verbal arguments that policymakers used in support of their preferred policies. ${ }^{2}$ The narrative approach has one great advantage: the reasoning and motivations of policymakers are likely to be best revealed by the arguments they originally used to support their positions. Our analysis focuses on the emergence of inflation during the 1970-1978 period when Arthur Burns chaired the Board of Governors.

Our discussion will proceed as follows. In section I, we sketch out the basic time inconsistency model of monetary policy and highlight the features of the analysis that we will subsequently document. In section II, we describe the FOMC documents from which we draw evidence to support our arguments. In section III, we consider the individual elements of the time inconsistency story. We first discuss external pressures on the FOMC to make the case that real economic activity was generally viewed as unsatisfactory. We then examine the Committee's views on the prevailing inflationunemployment tradeoff, the short-term nature of its policy actions, and the role of expectations in equilibrium. In section IV, we tie together the various threads of our analysis to construct an explanation of why inflation arose in the 1970s and not before. We discuss alternative explanations of the 1970s inflation in section V and offer some concluding remarks in section VI.

\footnotetext{
${ }^{2}$ Narrative approaches to the study of monetary policy were pioneered by Friedman and Schwartz (1963) and have recently been employed by Romer and Romer $(1989,2002)$.
} 


\section{The Basic Time Inconsistency Model of Monetary Policy}

Following the approach of Barro and Gordon (1983), assume that the economy is characterized by an expectations-augmented Phillips curve:

$$
u_{t}=u_{t}^{n}-\alpha\left(\pi_{t}-\pi_{t}^{e}\right), \alpha>0,
$$

where $u_{t}$ is the rate of unemployment, $u_{t}^{n}$ is the natural rate of unemployment, $\pi_{t}$ is the actual inflation rate, and $\pi_{t}^{e}$ is the expected inflation rate. ${ }^{3}$ Further, the natural rate of unemployment is stochastic and determined in accordance with

$$
u_{t}^{n}=\lambda \bar{u}^{n}+(1-\lambda) u_{t-1}^{n}+\varepsilon_{t}, 0<\lambda<1,
$$

where $\bar{u}^{n}$ is the constant long-run mean of the natural rate of unemployment, and $\varepsilon_{t}$ is a white noise disturbance. Equation (2) implies that unemployment is subject to shocks that are persistent, but not permanent. Further assume that the monetary authority directly controls the inflation rate, its policy instrument. The monetary authority must choose $\pi_{t}$ before observing $\varepsilon_{t}$, and it makes this choice to minimize the expected value of its quadratic loss function:

$$
L_{t}=\left(u_{t}-k u_{t}^{n}\right)^{2}+\beta\left(\pi_{t}\right)^{2}, \beta>0,0<k<1 .
$$

In equation (3), $k u_{t}^{n}$ represents a target value for unemployment. Because $k<1$, the target for unemployment is always below the prevailing natural rate. The parameter $\beta$ indicates the degree of inflation aversion. ${ }^{4}$

\footnotetext{
${ }^{3}$ We follow Barro and Gordon (1983) in assuming a linear Phillips curve. Tambakis (2002) develops related models in which the Phillips curve tradeoff is nonlinear.

${ }^{4}$ In the original Barro-Gordon paper, the monetary authority's loss function was assumed to be identical to that of society as a whole, but the model does not require this strong assumption. In our formulation, it is sufficient to require that the target rate of unemployment be less than the natural rate. Later contributions to the literature have noted that politicians might appoint conservative central bankers with the express
} 
Note that if the monetary authority could credibly commit to a particular inflation rate and if private agents recognized this commitment, then $\pi_{t}^{e}$ would equal $\pi_{t}$, and equation (1) would imply that unemployment would be equal to its natural rate in each period. Further, because $u_{t}$ would equal $u_{t}^{n}$ regardless of the rate of inflation, optimal policy would call for zero inflation.

Under period-by-period discretion, however, the situation will be different. In this case, the following sequence is played out in each period: (i) private agents form rational expectations of inflation for period $t$, so that $\pi_{t}^{e}=E_{t-1} \pi_{t}$; (ii) the monetary authority chooses the actual rate of inflation, $\pi_{t}$; and (iii) unemployment is determined via the Phillips curve given $\pi_{t}, \pi_{t}^{e}$, and the realization of the disturbance, $\varepsilon_{t}$. In step (ii), the monetary authority chooses $\pi_{t}$ by minimizing $E_{t-1} L_{t}$ subject to equations (1) and (2), treating expected inflation as given. The solution to this minimization problem requires that $\pi_{t}$ be set in accordance with

$$
\pi_{t}=\frac{\alpha}{\beta}(1-k) E_{t-1} u_{t}^{n},
$$

where $E_{t-1} u_{t}^{n}=\lambda \bar{u}^{n}+(1-\lambda) u_{t-1}^{n}$. Further, because rational private agents understand the monetary authority's decision problem, they correctly anticipate the chosen inflation rate, so that $\pi_{t}=\pi_{t}^{e}$. Equation (1) again implies that $u_{t}=u_{t}^{n}$ in each period, but now the

purpose of reducing the inflationary bias produced by the time inconsistency problem (Rogoff, 1985). Cukierman (2000) has shown that if there is uncertainty about the future state of the economy and if upward deviations of unemployment from the natural rate are penalized more heavily than downward deviations, then the inflation bias result holds even if the unemployment target coincides with the natural rate. 
inflation rate is greater than zero. Under discretion, policymakers cannot credibly commit to a policy of zero inflation.

Equation (4) indicates that the inflation rate varies (i) positively with the slope of the short-run Phillips curve, $\alpha$; (ii) positively with the gap between the unemployment target and its natural rate; $;^{5}$ and (iii) inversely with the monetary authority's disutility of inflation, $\beta$. Further, the model predicts that inflation will be higher when there are adverse supply shocks (i.e., when the expected natural rate of unemployment is higher). Finally, the model implies that if the monetary authority were to deviate from equilibrium by choosing a lower inflation rate $\left(\pi_{t}<\pi_{t}^{e}\right)$, then unemployment would exceed its natural rate; in the absence of credible commitment, pursuing a disinflationary policy would cause a recession.

\section{The Memoranda of Discussion and the Ford Library Transcripts}

Our arguments in this paper are based on an examination of textual records of FOMC deliberations on monetary policy. For the period from February 1970 through March 1976, our primary source of evidence is the FOMC's Memorandum of Discussion, which provides detailed summaries of meeting discussions. After March 1976, the FOMC stopped producing the Memorandum of Discussion. However, meeting deliberations were still secretly tape-recorded, transcribed, and stored at the Fed. In 1993, the Fed acknowledged the existence of these transcripts and since then has slowly produced edited versions for public release. Although the Fed has not yet released edited transcripts for the 1976-1978 period, copies of the original transcripts were included in

\footnotetext{
${ }^{5}$ A smaller value of $k$ implies a larger gap between the unemployment target and its natural rate; thus, $k$ is an indicator of the "degree of time inconsistency."
} 
Arthur Burns's papers archived in the Gerald Ford Presidential Library. We use these transcripts in studying the last two years of the Burns era.

Our original motivation in reading these source materials was not to investigate the time inconsistency issue. Rather, the original reading was required to code data on individual preferences on monetary policy targets for use in a quantitative analysis of FOMC decision- making (Chappell, McGregor, and Vermilyea, forthcoming). As we undertook that work, however, we simultaneously accumulated a file of items related to policy issues that have been widely discussed in the economics literature. As the file accumulated, we found that many of these items suggested to us that the time inconsistency problem played a role in the emergence and persistence of the inflation of the era. We then organized these items into the argument contained in the remainder of this paper.

The narrative approach does not permit us to rigorously test one hypothesis against possible alternatives, and it necessarily requires us to be selective in the arguments that we report. Nevertheless, we believe that the argument that follows provides a fair representation of the textual evidence upon which it is based.

\section{The Case for Time Inconsistency}

In this section, we draw on the Memoranda of Discussion and the Ford Library transcripts to document point-by-point key elements of the time inconsistency story of the 1970s inflation. We discuss (i) political and public preferences about economic performance, (ii) the short- and long-run Phillips curve tradeoffs, (iii) the period-byperiod nature of FOMC policymaking, and (iv) the role of expectations in equilibrium. 


\section{III.A. Political and Public Preferences About Economic Performance}

It is clear from the textual record that the FOMC takes pride in its independence. In our reading of the Memoranda and transcripts, we have not seen any comments that suggest that the Committee ever followed direct instructions from any outside authority.

However, the record also indicates that the preferences of external clients (the President, Congress, and the public) were noted and that the pressures they applied were felt.

During the 1970s, the message the Fed received consistently from these clients was that growth was too slow and unemployment too high.

In November 1970, for example, Governor William Sherrill cited public attitudes in advocating a more expansionary policy:

... if the staff's projections for 1971 were realized the nation would be paying a price, in terms of unemployment and underutilization of other resources, that was disproportionately high relative to the benefits that would be gained in the form of slower price advances. For the battle against inflation to take that form would, in his view, be unacceptable to the country. [Memorandum of Discussion, November 17, 1970, p. 1028, emphasis added]

Several months later, in June 1971, Burns commented on the risks to the System of an increase in the discount rate:

For the Federal Reserve to raise the discount rate at a time when unemployment was so high would lead many observers to wonder about the nature and purposes of the System and would produce strongly negative reactions in the Congress and the Administration ... at present he 
would expect to oppose such an action. [Memorandum of Discussion, June 8, 1971, pp. 594-595]

Later, in February 1974, the Committee again discussed acceptable inflationunemployment tradeoffs. In response to a comment by New York Fed President Alfred Hayes that an unemployment rate of 5.75 percent, as projected for the second quarter of that year, was not sufficient to justify a decisive move toward ease, Governor Jeffrey Bucher responded that it was also important to consider the tradeoff that Congress might consider appropriate:

Although many people now regarded a rate of unemployment in excess of 4 percent as acceptable, he was not convinced that Congress as a whole was prepared to accept a rate as high as 5 percent; certainly, it would not find a 6 percent rate acceptable. Committee members needed to be concerned about the effects that System policies might have on Congressional actions to deal with high unemployment and to recognize that, in the long run, the adverse effects of such actions on prices could be much greater than those of any marginal measures the System might take at this point. [Memorandum of Discussion, February 20, 1974, p. 191]

A year later, Boston Fed President Frank Morris argued that annual real growth as high as 5 percent was still inadequate as the economy moved into a recovery phase:

Mr. Morris observed that in his view acceptance of the staff projection led to the conclusion that the policy course being pursued by the Committee could not be defended before the Congress or the American people. Growth in real GNP of 5 per cent over the four quarters 
to the second quarter of next year, as projected, was not acceptable, and that slow a recovery could not be justified in the interest of dampening inflationary pressures. [Memorandum of Discussion, May 20, 1975, p. 596, emphasis added]

While pressures for growth are understandable when the economy is in recession, the political pressure for stronger growth persisted even when the economy had returned to an expansionary phase. In 1976, Jimmy Carter had campaigned on a promise not to reappoint Burns, but Burns nevertheless hoped to keep his job. Thus, in January 1977, the Chairman was ready to extend a signal of goodwill to the incoming President:

We have a new administration—the new administration has proposed a fiscal plan for reducing unemployment and any lowering of monetary growth rates at this time would, I'm quite sure, be very widely interpreted, and not only in the political arena, as an attempt on the part of the Federal Reserve to frustrate the efforts of a newly elected President [and a] newly elected Congress, to get our economy, to use a popular phrase, "moving once again.”[FOMC Transcripts, January 17-18, 1977, Tape 7, p. 2]

In sum, the FOMC's view during the Burns years was that output and unemployment had never reached politically acceptable levels. In terms of our model, while inflation was seen as undesirable $(\beta>0)$, political pressures caused the Fed to value unemployment below its natural rate $(k<1)$.

\section{III.B. Phillips Curve Tradeoffs}

The inflation-unemployment tradeoff was relatively stable during the 1950s and 1960s, leading some to believe that lower unemployment could be achieved, perhaps 
permanently, if society was willing to tolerate a moderately higher rate of inflation. By the late 1960s, however, the Friedman-Phelps natural rate hypothesis had questioned the likelihood of a permanent tradeoff between inflation and unemployment. Friedman (1968) and Phelps (1968) argued that in the long run, any attempt to exploit the Phillips curve tradeoff would lead to higher inflation but no permanent reduction in unemployment (i.e., unemployment would tend toward its natural rate in the long run). Their formulation underlies the Phillips curve of our model, provided by equation (1). Although the record of FOMC deliberations does not show that members accepted the Friedman-Phelps vertical long-run Phillips curve, it is clear that they appreciated two of its key features. First, the tradeoff between output and inflation was more favorable in the short run than in the long run. Second, inflationary expectations had an important effect on the outcomes that were feasible at a moment in time.

On the first point, consider the comments of Morris in July 1976:

I'd like to go back to [the] comment I wanted to make earlier on the usefulness of these alternative monetary [policy] formulations ... whenever you ask an economic model to give you the economic effects of the more expansionary policy over a fairly short period of time, you're up against the fact that the lags in the impact of monetary policy are much shorter on production than they are on prices, and I think every sheet of this kind that I have seen in the past eight years around this table suggested that a more expansionary policy would produce benefits in greater real growth and very little price effects, and I think that reflects the fact that the time horizon for this kind of exercise has got to be longer to 
be useful to the Committee. [FOMC Transcripts, July 20, 1976, Longer Run Targets, Tape 1, pp. 6-7]

On the second point, the role of expectational inertia in sustaining an inflation was clearly recognized as a complicating factor when Committee members considered efforts to slow the rate of price advances. In December 1970, Kansas City Fed President George Clay stated that "the current inflationary episode had proceeded so far and had become so involved in the wage-cost structure that there was serious doubt that the inflation could be curbed by any feasible monetary-fiscal policy mix ... Moreover, it had been and continued to be necessary for public economic policy to provide some stimulus to the economy" [Memorandum of Discussion, December 15, 1970, p. 1125]. Governor Charles Partee best stated the Committee's view, saying, "We certainly know that there's a built-in inflation rate of some considerable size resulting from the cost increases and the labor contracts [that] have been negotiated and will pay off regardless in this period to come" [FOMC Transcripts, February 28, 1978, Tape 4, p. 10, emphasis added]. Both of these comments not only illustrate recognition of the role of expectations in shifting the available Phillips curve tradeoff, but also make it clear that these expectations were essentially regarded as predetermined at the time of a meeting. It was common for Committee members to speak of the inflationary inertia as a cost-push phenomenon, emphasizing its exogeneity (as well as their lack of culpability) when advocating more stimulus.

Some Committee members explicitly adopted the view that the long-run Phillips curve might be vertical or nearly so. As early as May 1971, for example, St. Louis Fed 
President Darryl Francis noted that money growth and unemployment seemed to be unrelated over several extended episodes in the two previous decades: ${ }^{6}$

In each case, Mr. Francis continued, the rate of growth in money was accelerated in order to overcome weakness in the economy. Despite those progressively more stimulative monetary actions, the rate of unemployment had averaged about the same whether the trend growth of money was 6 per cent, 3.5 per cent, or 1.5 per cent. The trend growth had had its chief impact on prices, whereas fluctuations around the trend had had the greatest impact on production and employment. [Memorandum of Discussion, May 11, 1971, p. 476]

A month later, his comments again described the vertical long-run Phillips curve:

Mr. Francis said that such a slower growth in money would probably mean a less rapid recovery of production and employment, but one which was more likely to be sustained. Production and employment had risen at relatively rapid rates from 1962 to 1964 with a moderate 3.4 per cent average annual rate of growth of money. One might also observe that average unemployment since early 1967, when the growth rate of money had averaged more than 6 per cent, had been about the same as in the 1953-62 period when money had grown at an average 1.7 per cent rate. Production and employment benefits gained by accelerating money

\footnotetext{
${ }^{6}$ We should note that representatives of the St. Louis Fed represented a "monetarist" viewpoint that was distinctly different from the mainstream Committee view. Nevertheless, the central point that long- and short-run Phillips curves offered different tradeoffs seems to have been widely appreciated.
} 
upward from a previous trend had always been temporary. [Memorandum of Discussion, June 8, 1971, pp. 590-591]

In sum, the FOMC recognized Phillips curve constraints much like those assumed by time inconsistency theory. In the short run, the costs (in terms of output and employment) of reducing inflation seemed high. In the long run, ingrained inflationary expectations permitted high inflation and high unemployment to coexist. Furthermore, from the Committee's perspective, expectations-induced cost increases appeared to be exogenous at any single policy meeting. Therefore, even though the equilibrium inflation rate was high, the policy actions of reasonable policymakers sustained it.

\section{III.C. Period-by-Period Policymaking}

During the 1970s, FOMC members clearly perceived an unhealthy tension between their focus on policies to be selected for the next period and the longer-run consequences of those policies. As noted in the preceding section, Morris once complained that the policy alternatives presented to the Committee were based on a time horizon that was too short—a longer planning horizon was needed to show the eventual inflationary impact of a more stimulative policy. Burns's response to Morris neatly summarized the Committee's dilemma:

Let me just make a comment, that to do what we can in the way of longer run objectives, I think is salutary. ... But we have to do something very specific today. Mainly to set monetary growth ranges for the next 12 months for the interval between the second quarter of this year and the second quarter of next year. [FOMC Transcripts, July 20, 1976, Longer Run Targets, Tape 1, p. 7] 
In other words, the long run may be important, but it is not relevant to the subject of the Committee's decision to be made today. ${ }^{7}$

In October 1977, San Francisco Fed President John Balles commented that even hitting the 12-month targets was problematic. He noted that "... the Committee doesn't seem to have any systematic way of getting from here to there in terms of the two-month range versus the twelve-month range" [FOMC Transcripts, October 17, 1977, Tape 8, p. 10]. Finally, St. Louis Fed President Lawrence Roos summed up his experience on the Committee in this fashion:

I liken what we have done in the last year sort of to the alcoholic who should do something, but he takes a little drink this time and a little drink [next time] and he's always going to do something down the road ... We've set ranges until we're blue in the face ... we're just deluding ourselves if we think that we are really doing anything to correct the excessive growth of the money supply. [FOMC Transcripts, January 17, 1978, Tape 6, pp. 15-16]

Correcting the excessive money growth might have risked a recession, though, and we have seen in the previous subsections that political pressures and public opinion during the 1970s weighed against taking such risks. Thus, FOMC members may have been obliged to pursue short-term objectives even when they appreciated the risk for longerrun consequences.

\footnotetext{
${ }^{7}$ This point is also made by Lucas (1980, p. 208) in his assessment of rules versus discretion: "In the current system of discretionary economic management, no one or no small group ... is in a position to influence the economy in any significant way toward a regime of fixed, non-reactive policy rules. They are simply reacting, sometimes well, sometimes badly, to current difficulties, with no more capability of affecting policy five years hence than of affecting what happened five years before."
} 


\section{III.D. Expectations and Equilibrium}

The time inconsistency model is closed with an assumption of rational expectations. Although the Committee never seriously discussed the rational expectations hypothesis during the Burns era, it would be safe to assume that it was not a highly regarded notion. Despite this, it is useful as an assumption to make about equilibrium - in equilibrium, expectations about inflation and about policymaker actions should become correct. Furthermore, the strict rational expectations assumption is not essential for the key result regarding an inflationary bias. Although it is not widely appreciated, Nordhaus's (1975) article on political business cycles also included an analysis of inflation in a framework similar to that of Barro and Gordon (1983), but with adaptive rather than rational expectations assumed. ${ }^{8}$

FOMC members tended to view the public's expectations as largely inertial, but they also felt that financial markets often irrationally overreacted to perceived policy changes. ${ }^{9}$ Because of this, the Committee was very sensitive to how its policy decisions might be interpreted. At times, they clearly hoped to influence how expectations would change as their policy actions were revealed.

\footnotetext{
${ }^{8}$ In the Nordhaus model, adaptively formed inflation expectations converge to the equilibrium inflation rate in the long run and are in this sense "model-consistent."

${ }^{9}$ This once led San Francisco Fed President John Balles to propose publishing moving averages of money growth over several weeks rather than the money growth figure for just the most recent week (apparently presuming that market observers would be unable to infer the latest observation from the change in the average). He said, "I would publish the moving average to try to get away from what happened yesterday. Where the market reacted, in my opinion, in the wrong way to a single week's worth of figures. We've seen this repeated again and again and again and I am hoping that some day I can convince my colleagues around the table here to make some sort of device that we can publish ourselves so that the market would understand that there are a lot of random fluctuations in these weekly figures and indeed even the monthly figures." [FOMC Transcripts, July 20, 1976, Tape 1, p. 12]
} 
In October 1974, as the economy drifted into recession, the Committee's directive called for continued reductions in the federal funds rate. In the meeting, several members expressly argued that the easing should be carried out in a subtle fashion that would minimize expectational changes. Dallas Fed President Phillip Coldwell supported the easing, but opposed a discount rate change, noting that "in continuation of the gradual approach ... the System should not take any overt actions to ease at this time" [Memorandum of Discussion, October 14-15, 1974, p. 1133, emphasis added]. Burns argued that "any easing should be undertaken very cautiously" [p. 1124]. Atlanta Fed President Monroe Kimbrel "hoped that the System would not give the impression that it had abandoned its role in fighting inflation" [p. 1136], while Hayes added that "it was of crucial importance that the system not undermine the belief that it meant business about combating inflation" [pp. 1127-1128].

While these comments may reflect a sincere desire to avoid "irrational overreactions," it is also apparent that the Committee realized that the benefits from monetary stimulus would be stronger if the stimulus could be implemented without aggravating inflation expectations. Such motives are consistent with those attributed to policymakers in time inconsistency theory, even if the rational expectations assumption ultimately renders them futile.

\section{The Time Inconsistency Explanation of Inflation}

Thus far, we have argued that the Burns-era FOMC faced an environment that conforms to the theoretical setting for the time inconsistency problem and that the inflation of that era is compatible with its predicted equilibrium. Specifically, we have argued that FOMC documents indicate that policymakers desired unemployment lower 
than the natural rate, that they perceived an economy that could be characterized by an expectational Phillips curve, and that policy choices were made on a period-by-period basis without credible precommitment. Further, the FOMC believed that price expectations were essentially predetermined at the time of a policy meeting, but also knew that these expectations contributed to inflationary momentum over longer horizons. These are key ingredients in the theory of the time inconsistency problem. We have also noted that members occasionally voiced frustration with their inability to escape what appeared to be a suboptimal inflationary outcome.

However, an obvious question arises: Why was inflation high in the Burns years compared to other periods? Mayer (1999, p. 8) argues that if the time inconsistency problem is to provide a convincing explanation for the Great Inflation, one must claim that the assumptions of the theory fit that time period more closely in the 1970s than at other times. ${ }^{10}$ As in many economic models, predictions of time inconsistency theory are best expressed as comparative static results. The equilibrium inflation rate depends on the parameters of the model, and when those parameters change, the model predicts changes in inflation as well. Mayer's observation that inflation was higher in the Burns years than other times is not a refutation of the theory; rather, it requires us to ask if there is a comparative static interpretation of the emergence of inflation that is consistent with the predictions of the model. In this section, we argue that this is the case.

Recall equation (4), which provides the equilibrium inflation rate in our model:

\footnotetext{
${ }^{10}$ Mayer also draws on FOMC documents, including the Memoranda of Discussion, as well as interviews with former FOMC members, former staff economists, and former CEA chairmen. Mayer did not use the Ford Library transcripts in his analysis, nor did he focus on time inconsistency theory; rather, he offered only a brief discussion of why he chose not to use time inconsistency as an analytical framework.
} 


$$
\pi_{t}=\frac{\alpha}{\beta}(1-k) E_{t-1} u_{t}^{n}
$$

According to (4), the economy's equilibrium inflation rate depends on the short-run Phillips curve tradeoff (parameter $\alpha$ ), the monetary authority's aversion to inflation versus output (parameter $\beta$ ), the gap between target and natural rates of unemployment (determined by the parameter $k$ ), and the expected value of the natural rate of unemployment. In our view, it is plausible that changes in parameters and the natural rate of unemployment led to higher equilibrium inflation rates in the 1970s.

First, consider the preferences of policymakers. It probably requires little effort to convince most readers that Richard Nixon was more averse to economic downturns than most other Presidents. He blamed his 1960 presidential election loss on a stagnating economy and was determined that there should be no repetition in $1972 .{ }^{11}$ In August 1971, with inflation becoming a threat, Nixon took an unprecedented step, imposing wage and price controls in a peacetime environment. It is fairly clear that this was done so that he could fight inflation without imposing monetary or fiscal restraint that might lead to recession. Governor Andrew Brimmer noted as much in an April 1972 FOMC meeting:

Mr. Brimmer observed that there also was a continuing problem of inflation, despite the control program that had been in effect since midAugust 1971 ... The significant point was that the Administration had decided at that time-with the support of the Congress and the Federal Reserve- that the way to solve the problem of inflation was to apply

\footnotetext{
${ }^{11}$ Nixon (1962, pp. 309-312) describes his view of the 1960 election.
} 
direct controls rather than to slow the rate of economic growth and increase excess capacity. [Memorandum of Discussion, April 17-18, 1972, pp. 447-448]

Burns and the FOMC recognized that raising interest rates when prices and wages were controlled might be politically dangerous:

So long as interest rates in general remained below the levels that had prevailed before the President's address he [Burns] did not think much pressure would build up for including them in the freeze. The situation would be different, of course, if rates were to move back up above those levels. [Memorandum of Discussion, August 24, 1971, pp. 810-811, emphasis added]

The awkwardness of the Fed's position was magnified by Nixon's decision to name Arthur Burns the Chairman of the Committee on Interest and Dividends (CID), the administrative unit charged with overseeing policy toward interest rates and dividends during the period of wage and price controls. ${ }^{12}$ Arguably, the Administration limited monetary policy options during this period by the implied threat of imposing rigid controls on interest rates if the Fed behaved inappropriately. Nixon's obsession with ensuring rapid output growth and high employment in 1972, when he faced re-election, led him to take extraordinary actions that effectively imposed altered preferences on the Fed. These preference changes plausibly took the form of a lower value for $k$, which would imply a lower unemployment rate target, and a lower value for $\beta$, the relative

\footnotetext{
12 The difficulties Burns faced in his simultaneous roles as Fed Chairman and CID Chairman are discussed by Kettl (1986) and Wells (1994).
} 
concern for inflation versus output. Either of these shifts would lead to a prediction of higher equilibrium inflation.

While a politically induced change of preferences seems plausible in this case, using preference changes to explain varying outcomes is often a last resort for economists. Because preferences are not directly observed, explanations based on preference changes are difficult to refute, even when incorrect. We therefore turn to a second comparative static argument, this one based on supply shocks $\left(\varepsilon_{t}\right)$ that result in persistent shifts in the natural rate of unemployment.

Our premise is that the natural rate of unemployment rose in the 1970s.

Economists are largely in agreement with this assessment. For example, Gordon (1981) estimated that the natural rate of unemployment rose from 4.7 percent to 5.4 percent from the mid-1960s to the mid-1970s. ${ }^{13}$ Evidence from Committee deliberations suggests that FOMC members recognized that such changes had occurred. For example, in July 1977, Chicago Fed President Robert Mayo observed, "Even the goal of 6 percent unemployment seems difficult to attain these days" [FOMC Transcripts, July 19, 1977, Tape B, p. 4]. Later in the same meeting, this issue came up again, along with a reference to what the politicians might find acceptable [FOMC Transcripts, July 19, 1977, Tape B, p. 9]:

Zeisel (staff): I think in terms of our reference toward unemployment, I think one has to, as you know, recognize structural changes that have tended to occur in the labor market [that] tended to bias up the

\footnotetext{
13 These estimates would be close to those generally made by economists in the 1970s. With the benefit of hindsight, it now appears that the natural rates of unemployment during this period were higher than previously thought -5.6 percent in the mid-1960s and 6.0 percent in the mid-1970s, according to more recent estimates by Gordon (1993).
} 
unemployment rate and in addition we've just been through a period of enormous growth in the labor force which was very largely made up of women who tend to have high frictional rates of unemployment. I think the 6-1/4 per cent rate, really, for comparison with past periods, has to be adjusted down somewhat.

Partee: You mean 6-1/4 might be a pretty good rate of unemployment.

Zeisel: Well 6-1/4 by capacity, yes.

Partee: Although I haven't heard anything here in the city that would suggest acceptance of that.

This exchange reveals that the FOMC had recognized an exogenous upward shift in the natural rate of unemployment, which, according to our model, leads to higher inflation. ${ }^{14}$ The exchange also confirms our earlier suggestion that the gap between the natural rate and the politically determined target had widened. A wider gap (smaller $k$ ) between natural and target rates of unemployment also leads to a comparative static prediction that equilibrium inflation should rise. Thus, the rise of inflation during the Burns era appears to be compatible with the comparative static implications of time inconsistency theory. Further, the subsequent fall of inflation in the 1980s could reflect a moderation of political preferences and a reversal of demographic trends affecting natural rates. $^{15}$

\footnotetext{
${ }^{14}$ Later in the same year, on September 20, the Committee talked at length about the full-employment unemployment rate. In particular, there was some discussion of a Wall Street Journal article by Herbert Stein, in which Stein had suggested that the full-employment unemployment rate might be as high as 7.0 percent.

${ }^{15}$ The Volcker disinflation occurred after a change in administrations resulted from the election of Ronald Reagan, who, at least initially, appeared to be more inflation averse than his predecessors. In addition, estimates of the natural rate of unemployment show declines beginning in the early 1980s (Gordon, 1997).
} 


\section{Alternative Explanations for the Great Inflation}

We have argued that contemporaneous accounts of FOMC policy discussions support the view that time inconsistency theory provides a plausible explanation for the emergence of inflation in the Burns era. In this section, we will briefly discuss two competing explanations. The first of these emphasizes the importance of mistakes and misperceptions; the second emphasizes the role of exogenous shocks to food and energy prices.

Mayer (1999) notes that forecasting errors may have led to policy mistakes and subsequent inflation in the 1970s. He argues that the Burns-era FOMC consistently under-predicted the inflation rate and over-predicted the unemployment rate, leading it to advocate more expansionary policies than it otherwise would have. Similarly, Orphanides (2002, p. 7) finds that policy choices in the 1970s "were consistent with application of a 'modern' systematic, activist, forward-looking approach to policy." Those policies produced poor outcomes because of policymaker misperceptions, specifically misperceptions about the natural rate of unemployment. Given these findings, we cannot dismiss the possibility that policy mistakes played a role in the increase in inflation in the 1970s. However, we can offer two arguments against the "mistakes" hypothesis.

First, while forecasts and perceptions could not always be perfectly accurate, FOMC records also make it clear that the Committee realized that its actions risked exacerbating, or at least sustaining, inflation. Members viewed the tradeoffs that they confronted as unpalatable choices, but they frequently chose to favor short-run output concerns over longer-term inflation consequences. Second, if mistakes were made, their consequences were eventually revealed. If the rise of inflation was a consequence of 
mistakes, why were the mistakes not corrected more quickly when inflation was observed? The fact that the Committee persistently kept the federal funds rate low in the face of repeated money growth overshoots and high inflation rates suggests that the Committee could not bring itself to endure the consequences of producing lower inflation. Explanations relying on "mistakes" to explain such large and persistent accelerations of inflation are, at best, incomplete.

The second alternative explanation for the emergence of inflation in the 1970s stresses exogenous shocks to food and energy prices. Conventional wisdom attributes much of the inflation of the period to supply shocks, and there is little doubt that such shocks complicated the policymaking task of the FOMC. However, supply shocks do not necessarily produce persistent inflations. Consider the comments of current Federal Reserve Governor Ben Bernanke, who argues against a significant role for oil prices in the emergence of the Great Inflation of the 1970s:

My reading of the evidence suggests that the role the conventional wisdom has attributed to oil price increases in the stagflation of the 1970s has been overstated, for two reasons. First, the large increases in oil prices that occurred in this period would not have been possible in an environment that was not already highly inflationary because of previous monetary expansion ... Second, without Fed accommodation, higher oil prices abroad would not have translated into domestic inflation to any significant degree [Bernanke, Speech to the Money Marketeers of New York University, February 3, 2003] 
In the FOMC's meeting in August 1975, oil prices and inflation were discussed at some length. In his introductory briefing, Fed staff economist Lyle Gramley suggested that the Committee should accommodate exogenously higher food and energy prices with more rapid money growth, even though real output growth was expected to be robust:

Price increases of these dimensions, coming at a time of a rebound of real GNP growth to the 7 to 8 percent range, would ... put inordinate strains on financial markets if growth rates of the monetary aggregates were held to the midpoints of the current target ranges. Our GNP projection assumes, therefore, that growth rates of the major aggregates would be permitted to drift toward the upper end of the current ranges ... [Memorandum of Discussion, August 19, 1975, p. 923]

St. Louis Fed Vice President Gene Leonard countered that the impact of the price shocks also affected capacity constraints and, by extension, natural rates of output and unemployment:

Continuing, Mr. Leonard said the rationale for a highly stimulative policy rested in part on the large amount of unused resources available in the economy ... He would suggest that the special factors—such as the poor crops and the energy shortages— that had reduced output in 1973-1974 also had reduced capacity ... In his opinion the limits of economic capacity would be reached much sooner than the inflationists believed. [Memorandum of Discussion, August 19, 1975, p. 925]

Philadelphia Fed President David Eastburn further objected that it was difficult to distinguish exogenous and endogenous price changes: 
Mr. Eastburn commented that he was concerned by the distinction that had been made between exogenous and endogenous price movements and, specifically by the notion that the increases in prices of foods and fuels were exogenous and had to be accommodated. He had difficulty in distinguishing between the effects of those increases and the increases in steel, aluminum, and autos, and he felt that an accommodative posture too easily could lead to acceptance of inflation. [Memorandum of Discussion, August 19, 1975, p. 933]

Gramley responded that since other prices were downwardly rigid, accommodation of the food and energy price increases was necessary to maintain real growth:

Given the demand and supply conditions for [foods and energy], an adjustment in relative prices had to take place, and because of the downward inflexibility of most prices, it was just about impossible to get the adjustment in relative prices without a rise in the general level of prices. Thus, if policy did not accommodate the price increases for foods and ene rgy by permitting a higher rate of monetary expansion, the rate of growth in real GNP would be reduced. [Memorandum of Discussion, August 19, 1975, p. 933]

Chairman Burns then reinforced Eastburn's point:

Price increases were always occurring because of factors that might be classified as exogenous, and if policy always accommodated such increases, it would be validating a never-ending inflationary trend. [Memorandum of Discussion, August 19, 1975, p. 934] 
In this exchange, Burns and Eastburn clearly anticipated Bernanke's point that a supply shock requires monetary accommodation to produce inflation. Despite the antiinflationary rhetoric expressed during this meeting, Burns and the FOMC ultimately chose to leave the funds rate target unchanged, effectively adopting a policy of accommodation.

The preceding discussion suggests that supply shocks were relevant to the inflationary process, but in a way that is compatible with the theory of the time inconsistency problem. If the FOMC had consistently followed a Friedman-type kpercent money growth rule in the 1970s, inflation would not have accelerated as it did. However, the time inconsistency theory implies that unfavorable shocks to natural rates will affect monetary policy and the equilibrium rate of inflation. When the equilibrium inflation rate rises, inflation expectations rise as well. Changing expectations are in turn reflected in wages and prices, and policymakers see what they perceive to be a "costpush" phenomenon. In the midst of this "cost-push" inflation, policymakers recognize that failure to accommodate will precipitate recession. As a result, they choose to "ratify" the higher equilibrium inflation rate, as they apparently did in August 1975. It is precisely this comparative static result that lies at the heart of both Ireland's (1999) econometric support for time inconsistency theory and our argument in section IV of this paper.

\section{Conclusions}

As this paper is being written, inflation is low and Federal Reserve policymakers seem confident that the experience of the 1970s will not be repeated. However, if the theory of the time inconsistency problem provides a plausible explanation for the rise of inflation in the 1970s, it does not suggest that complacency is appropriate. Policymakers 
may have greater appreciation for the importance of maintaining price stability, but the fundamental institutions by which monetary policy decisions are made have not changed, nor has the broader political environment. Shocks similar to those that emerged in the 1970s could do so again. While Blinder (1997) would comfort us with the argument that the time inconsistency problem is no longer relevant, a more troubling interpretation is possible. The current time-consistent equilibrium is more pleasant than the one prevailing in the 1970s, not just because the Fed is more enlightened, but also because of a fortunate confluence of exogenous economic and political forces. 


\section{References}

Barro, Robert J., and David B. Gordon. 1983. "A Positive Theory of Monetary Policy in a Natural Rate Model.” Journal of Political Economy 91 (4): 589-610.

Bernanke, Ben S. 2003. "Constrained Discretion and Monetary Policy." Speech given to the Money Marketeers of New York University, New York, February 3, 2003.

(http://www.federalreserve.gov/boarddocs/speeches/2003/20030203/default.htm)

Blinder, Alan S. 1997. "What Central Bankers Could Learn from Academics - and Vice Versa." Journal of Economic Perspectives 11 (2): 3-19.

Chappell, Henry W. Jr., Rob Roy McGregor, and Todd Vermilyea. Forthcoming. "Majority Rule, Consensus Building, and the Power of the Chairman: Arthur Burns and the FOMC." Journal of Money, Credit, and Banking.

Cukierman, Alex. 2000. “The Inflation Bias Result Revisited.” Working paper.

DeLong, J. Bradford. 1997. “America's Peacetime Inflation: The 1970s.” In Christina D. Romer and David H. Romer, eds., Reducing Inflation: Motivation and Strategy (Chicago, IL: University of Chicago Press): 247-276.

Friedman, Milton. 1968. "The Role of Monetary Policy." American Economic Review 58 (1): 1-17.

Friedman, Milton, and Anna J. Schwartz. 1963. A Monetary History of the United States, 1867-1960. Princeton, NJ: Princeton University Press.

Gordon, Robert J. 1981. Macroeconomics, $2^{\text {nd }}$ edition. Boston, MA: Little, Brown, and Company.

Gordon, Robert J. 1993. Macroeconomics, $6^{\text {th }}$ edition. New York, NY: HarperCollins College Publishers.

Gordon, Robert J. 1997. "The Time-Varying NAIRU and its Implications for Economic Policy." Journal of Economic Perspectives 11 (1): 11-32.

Ireland, Peter N. 1999. "Does the Time-Consistency Problem Explain the Behavior of Inflation in the United States?" Journal of Monetary Economics 44 (2): 279-291.

Kettl, Donald F. 1986. Leadership at the Fed. New Haven, CT: Yale University Press.

Kydland, Finn E., and Edward C. Prescott. 1977. "Rules Rather than Discretion: The Inconsistency of Optimal Plans." Journal of Political Economy 85 (3): 473-491. 
Lucas, Robert E. 1980. "Rules, Discretion, and the Role of the Economic Advisor." In Stanley Fischer, ed., Rational Expectations and Economic Policy (Chicago, IL: University of Chicago Press): 199-210.

Mayer, Thomas. 1999. Monetary Policy and the Great Inflation in the United States: The Federal Reserve and the Failure of Macroeconomic Policy, 1965-79. Cheltenham, UK: Edward Elgar.

Nixon, Richard. 1962. Six Crises. Garden City, NY: Doubleday.

Nordhaus, William D. 1975. "The Political Business Cycle." Review of Economic Studies 42 (2): 169-190.

Orphanides, Athanasios. 2002. "Monetary Policy Rules and the Great Inflation" Working paper, Board of Governors of the Federal Reserve System.

Persson, Torsten, and Guido Tabellini. 2000. Political Economics: Explaining Economic Policy. Cambridge, MA: The MIT Press.

Phelps, Edmund S. 1968. "Money-Wage Dynamics and Labor Market Equilibrium." Journal of Political Economy 76 (4, Part 2): 678-711.

Rogoff, Kenneth. 1985. "The Optimal Degree of Commitment to an Intermediate Monetary Target." Quarterly Journal of Economics 100 (4): 1169-1189.

Romer, Christina D., and David H. Romer. 1989. "Does Monetary Policy Matter? A New Test in the Spirit of Friedman and Schwartz." NBER Macroeconomics Annual (Cambridge, MA: The MIT Press): 121-170.

Romer, Christina D., and David H. Romer. 2002. "The Evolution of Economic Understanding and Post-War Stabilization Policy," Rethinking Stabilization Policy (Kansas City, MO: Federal Reserve Bank of Kansas City): 11-78.

Tambakis, Demosthenes N. 2002. "Expected Social Welfare Under a Convex Phillips Curve and Asymmetric Policy Preferences." Journal of Money, Credit, and Banking 34 (2): 434-449.

Wells, Wyatt C. 1994. Economist in an Uncertain World: Arthur F. Burns and the Federal Reserve, 1970-78. New York, NY: Columbia University Press. 